\title{
Self-efficacy, emotional intelligence, and quality of life amongst cancer patients
}

\begin{abstract}
Background: This research examined the self-efficacy, emotional intelligence, and quality of life among cancer patients, predominantly focusing on patients with either breast cancer or GI cancer. The purpose of the study was to identify and investigate the relationship between the psychological factors of self-efficacy, emotional intelligence and quality of life among cancer patients.
\end{abstract}

Method: This is a cross-sectional study which involved a sample of both females and males participants, diagnosed with GI cancer or breast cancer, $(\mathrm{N}=86)$, were aged above 18years old and had achieved a minimum level of education up to secondary. Therefore, this ensured they were able to read and understand the psychological tests.

The tools used were: the Schutte Self-Report Emotional Intelligence Test, The General Self-Efficacy Scale and The SF-12 of quality of life scale.

Result: The results showed a correlation between the self-efficacy and emotional intelligence, and a statistically significant relationship between the self-efficacy and quality of life on the physical domain only. In addition, there is a gender and diagnosis type differences, with male cancer patients having higher self-efficacy in comparison to female cancer patients. Furthermore, the GI cancer patients both genders had a higher self-efficacy than the breast cancer. However, females have higher quality of life in terms of the mental health domain in comparison to males.

Conclusion: The results emphasise the paramount importance of psychological intervention to asses and provide cancer patients with a psychological program to enhance the self-efficacy for cancer patients (breast and GI cancer) to improve and modify the quality of life for the patient.

Keywords: self efficacy, emotional intelligence, quality of life, cancer
Volume 9 Issue 5 - 2018

\author{
Suad Hassan Hashim,' Mohamed S Khalil ${ }^{2}$ \\ 'Clinical Psychologist, Neuroscience center, Department of \\ Mental , King Fahad Specialist Hospital Dammam, Saudi Arabia \\ ${ }^{2}$ Associate Professor/Consultant Clinical Psychologist, \\ Department of Psychiatry, College of Medicine, Imam \\ Abdulrahman Bin Faisal University, King Fahad University \\ Hospital, Saudi Arabia
}

Correspondence: Suad Hassan Hashim, Clinical Psychologist, Neuroscience center, Department of Mental Health, King Fahad Specialist Hospital Dammam, Saudi Arabia,, Tel +966542182320, Emailmesu22@gmail.com

Received: August 29, 2018| Published: September 12, 2018

\section{Introduction}

Cancer is has been described as a leading cause of death worldwide, accounting for 8.8 million deaths in $2015 .{ }^{1}$ Cancer is usually caused by the transformation of normal cells into tumour cells, in a multistage complex process that generally progresses from a pre-cancerous lesion to a malignant tumour eventually. ${ }^{1}$ It is the second-mostcommon cause of death in the United States, surpassed only by heart disease, and is the leading cause of death worldwide. ${ }^{1}$ This highlights the magnitude of the problem cancer presents to even a developed country. According to the Saudi Oncology Society, "the Saudi Cancer Registry (SCR) in 2010 was 13,706 . Overall, cancer was slightly more prevalent among women than men". ${ }^{2}$ Such a physical health problem that patients face who have been diagnosed with cancer also has the potential to cultivate a psychological problem for the patient too. In addition, without adequate help and early therapy intervention to deal with the psychological aspect, this may lead to other issues long term. Here are a few examples of the thoughts of actual cancer patients "I am punished for something I did or failed to do in the past." Some patients contemplate that if they had just done what they knew was right; they would not have developed cancer. Most patients wonder and question themselves if they somehow caused cancer themselves. Research into physical, psychological, social, and environmental factors suggested that psychosocial support was considered as one of the top factors that can improve the quality of life in cancer patients. ${ }^{3}$ Many studies examine the relationship between the emotional intelligence and quality of life.
Mayer et al., ${ }^{4}$ described the concept of Emotional Intelligence (EI) as the capacity to reason about emotions, and the capacity of emotions to enhance thinking. EI includes the abilities to accurately perceive emotions, access and generate emotions in order to assist thoughts, to understand emotions and emotional knowledge, and to reflectively regulate emotions in order to promote emotional and intellectual growth. On the other hand, several studies have examined the relationship between self-efficacy and quality of life. Self-efficacy refers to an individual's belief in his or her capacity to execute behaviours necessary to produce specific performance attainments. Self-efficacy reflects confidence in the ability to exert control over one's own motivation, behavior, and social environment. ${ }^{5-7}$ Emotional intelligence and self-efficacy play essential roles in patients' quality of life, as concluded in a study conducted by Amirifard et al., ${ }^{8}$ who investigated the relationship between emotional intelligence and the quality of life was discussed. In addition, Moradi et al., ${ }^{9} \&$ De Castro et al., ${ }^{10}$ investigated the association between self-efficacy and the quality of life for cancer patients and identified a positive correlative relationship between the two. This research topic concerns self-efficacy, emotional intelligence, and quality of life among cancer patients. The topic was chosen for the following reasons: firstly is occupational, namely to study and understand the relationships between and the effects on the quality of life for cancer patients in relation to the psychological factors of self-efficacy and emotional intelligence; secondly, is that there is a research gap in information and knowledge about cancer patients related to the psychological factors of self-efficacy and emotional intelligence, in particular focusing on 
cancer patients from Saudi Arabia. Lastly, for educational purposes the university enhance and support the health psychology approach for patients, therefore this research will cover the three mentioned psychological factors covering the eastern province of the Kingdom of Saudi Arabia.

\section{Statement of the problem}

Psychological intervention is of paramount importance for the patient to improve their quality of life both in terms of physically and mentally related to psychological factors from the health and psychoncology prospective. At present, there is a gap of study in the Middle East and Saudi Arabia about the psychological support available for cancer patients. However, this study aims to examine the selfefficacy, emotional intelligence, and quality of life for patients who have cancer in Saudi Arabia. The study finding will provide and guide the psychologist and all the treating team with knowledge, to deliver an appropriate psychological plan starting from the assessment ending with intervention for the patient, from evidence based research. The study hypotheses 1) There are significant relationships between cancer patient's self-efficacy, emotional intelligence, and quality of life (DV). 2) Sociodemographic factors will show significant effects of these psychological variables (DV). 3) Types of cancer will show significant effects of these psychological variables (DV).

\section{Methodology design and setting}

The study uses descriptive correlation (cross-sectional) design to investigate the relationship emotional intelligence, self-efficacy and quality of life, as dependent variables, with cancer types and sociodemographic factors as independent variables. A descriptive design is useful to create a snapshot of the current state of affairs. A correlation design is used to assess the relationships between two or more variables. ${ }^{11}$ In this way, the research design will help in clarifying the dynamics of the patients' psychological responses and their consequent physiological effects. It might also be the case that extraneous variables will affect the artefact outcomes. The proposed sample method is convenience sampling, which is more suitable for this kind of research. In this type of sampling design, a convenience sampling technique was used. All the patients were from King Fahad Specialized Hospital-Dammam tertiary hospital in the eastern province of Saudi Arabia.

\section{Participants}

All participants were Saudi people from various regions in Saudi Arabia. They are aged 18 years old and above, included both genders, and had a minimum high school graduation status and above to confirm that they were able to read and understand the psychological tests. Convenience sampling is also the most suitable for the study's control and limiting of the extraneous variables, such as education level and age. These might have effects on the study's result due to the participants' varying maturity and education level. ${ }^{12}$ Some patients who were approached and asked to partake, refused to participate in the study, as people in Saudi Arabia consider themselves conservative and the issue of personal health as private, or in the alternative, their adverse decision might be for personal reasons.

\section{Materials}

For the proposed psychological testing, the study used the following standard protocol psychological tests: Salovey \& Mayer ${ }^{13}$ proposed the emotional intelligence test the Schutte ${ }^{14}$ Self-Report Emotional Intelligence Test (SSEIT) as a method of measuring general emotional intelligence. The SSEIT arises from the emotional intelligence model. The SSEIT assesses perception, understanding, expression, regulating and harnessing of emotion in the self and others. ${ }^{14}$ The Schutte Emotional Intelligence was translated and adopted to Arabic. (Dr. Amantaniouse Mikhail, Damascus University, 2015). Scoring and interpretation: the (SEIS) comprises of 33 selfreferencing statements and requires subjects to rate the extent to which they agree or disagree with each statement on a five-point scale (one=strongly disagree; five $=$ strongly agree) the items $(3,28$ and 33) are reverse on the (Ciarrochi et al., 2000). Participants reply on a Likert scale and a total score is derived by summing up the item responses (Petrides \& Furnham, 2000). The overall score range is from 33 to 165 .

The General Self-Efficacy Scale is a 10 items developed by Ralf Schwarzer and translated by Issa Almansour ${ }^{15}$ Psychometric scale that is designed to assess optimistic self-beliefs to cope with a variety of difficult demands in life. The scale was originally developed in German by Matthias Jerusalem and Ralf Schwarzer in 1981 and has been used in many studies with hundred thousand of participants. In contrast to other scales that were designed to assess optimism, this one explicitly refers to personal agency such as the belief that one's actions are responsible for successful outcomes. Perceived self-efficacy is a prospective and operative construct. Scoring and interpretation: there are four ways to respond ( 1 is not at all true, to 4 exactly true), the responses are then summated to give an overall score range from 10 to 40 points.

SF-12: is a short version of the SF-36 developed by the Health Assessment Lab at the New England Medical Center (Kondo et al. 2013).Items are used to measure functional health and physical domains from the patient's point of view. The SF-12 Survey is a shorter version of the SF-36 Survey that uses just 12 questions to measure the same domains. The sub-domains are Physical Functioning; RolePhysical (RP), Bodily Pain (BP), General Health (GH), Vitality (VT), Social Functioning (SF), Role-Emotional (RE), Mental Health (MH), and Reported Health Transition. (John E. \& Ware, Jr, 2014) Alshehri, and Khalil, ( Alshehri, et al, 2008) reported that the academic translator at the King Fahd University Hospital Medical Education Centre translated the document from English to Arabic. For the sake of content validity, three consultants from the Department of Family and Community Medicine reviewed the Arabic version. They translated it to English again and their translation was compared with the original English version of the questionnaire. A pilot study was conducted at one primary health care center among 20 patients (10 males and 10 females) with diabetes. As a result of this pilot study, the wording was slightly altered for better understanding of the questions. In testing the reliability of the translated questionnaire. ${ }^{16}$

\section{Result}

(Table 1) Sociodemographic and other characteristics of the participants $(\mathrm{n}=86)$ the participants were all adult cancer patients, with an age ranged between 27 and 76 years old. From this, 56\% of the sample was older than 40 year old and $44 \%$ younger than 40 year old. The majority of the sample participants were females $(73 \%)$ while the males represented only $27 \%$ of the sample. Most of the diagnostic group were represented by breast cancer $(65 \%)$ while GI cancer 
represented $35 \%$ of the sample. Similarly, the numbers of outpatients were more $(65 \%)$ than the inpatient $(35 \%)$ of the participants (Figure 1).

Table I Sociodemographic and other characteristics of the participants $(n=86)$

\begin{tabular}{ll}
\hline Characteristics & Frequency n $(\%)$ \\
\hline Sex & $23(26.7)$ \\
Male & $63(73.3)$ \\
Female & \\
Age & $38(44.2)$ \\
Less than 40 years & $48(55.8)$ \\
40 years or above & $8(9.3)$ \\
Marital status & $69(80.2)$ \\
Single & $8(9.3)$ \\
Married & $1(1.2)$ \\
Divorced & $30(34.9)$ \\
Widow & $56(65.1)$ \\
Type of patient & \\
Inpatient & \\
Outpatient & \\
Diagnosis & \\
Breast Cancer & \\
GI & \\
\hline & \\
\hline
\end{tabular}

The participant's educations level. The vast majority of participants had completed bachelor and high school $(44 \%-43 \%)$, the diploma

Table 2 Correlation

\begin{tabular}{|c|c|c|c|c|c|}
\hline Total EI & & Total SE No & Total SF-12 (Scaled Scores) & PH SCORE & MHC SCORE \\
\hline Total EI & 1 & $.404 * *$ & 0.072 & 0.041 & 0.064 \\
\hline Total SE No & $.404 * *$ & 1 & -0.004 & $.218 *$ & -0.164 \\
\hline Average of $\mathrm{t}$ transformed from $\mathrm{z}$ score & 0.072 & -0.004 & 1 & $0.762 * *$ & $0.799 * *$ \\
\hline PH score & 0.041 & $.218^{*}$ & $0.762 * *$ & 1 & $0.248^{*}$ \\
\hline MHC score & 0.064 & -0.164 & $0.799 * *$ & $0.248^{*}$ & 1 \\
\hline
\end{tabular}

Table 3 Manova for All IV

\begin{tabular}{llll}
\hline \multicolumn{4}{l}{ Multivariant analysis of variance: all IV (Demographic and clinical). } \\
\hline Wilks' Lambda & Value & $\mathrm{F}$ & Sig. \\
Gender & 0.307 & $3.45 \mathrm{~b}$ & $0.01 \mathrm{I}$ \\
Age & 2.170 & 1.03 & 0.416 \\
Education & 0.326 & .74 & 0.775 \\
Marital & 0.265 & .8 & 0.681 \\
Diagnosis & 0.380 & 4.78 & 0.002 \\
Type & 0.135 & 1.22 & 0.319
\end{tabular}

represented significantly less $(7 \%)$, as well as those holding a Ph.D. $(4 \%)$ and master $(2 \%)$.

A significant correlation was found between emotional intelligence and self-efficacy as presented in table $2(\mathrm{R}=0.40, \mathrm{P}=0.001$; Pearson test), and between self-efficacy and the $\mathrm{PH}$ score (physical health) of the SF- 12 ( $\mathrm{R}=0.22, \mathrm{P}=0.05$; Pearson test $)$. The correlations between the PCS and MCS components of the SF-36 and SF-12 scales were also highly significant $\left(\mathrm{R}=0.76\right.$ to $0.80 ; \mathrm{P} \_0.001$; Pearson test (Table 2). Table 3 presents the results of MANOVA which shows that the gender and type of cancer have significant effects on self-efficacy. The male's self-efficacy was higher than the females and patient with GI cancer has higher self- efficacy than the breast cancer patients $\mathrm{P}<0.05$.

Figure I Distribution of education level among the study participants.

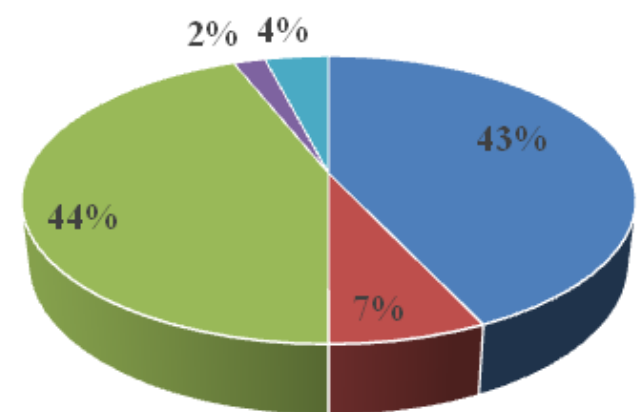

- High school - Diploma $\square \mathrm{BA}$ - $\mathrm{MA}=\mathrm{PHD}$

Table 4 Univariate Analysis of the effects of gender, diagnosis on Self Efficacy and MHC score of SF-12.

Table 5 presents the result of regression analysis which shows a significant predictive effect of gender, diagnoses, and types of patients (outpatient/inpatient) on the score of self-efficacy. 
Table 4 Univariate analysis

\begin{tabular}{|c|c|c|c|c|c|}
\hline Dependent variable & Sum of Squares & df & Mean Square & $\mathbf{F}$ & Sig. \\
\hline Total EI & 2.24 & 1 & 2.24 & 0.02 & 0.898 \\
\hline Total SE No & 187.03 & 1 & 187.03 & 6.32 & 0.016 \\
\hline Average of transformed from $\mathrm{z}$ score & 12.09 & 1 & 12.09 & 3.16 & 0.083 \\
\hline PHscore & 6.66 & 1 & 6.66 & 1.21 & 0.278 \\
\hline MHCscore & 35.42 & 1 & 35.42 & 5.55 & 0.023 \\
\hline
\end{tabular}

The F tests the effect of Diagnosis. This test is based on the linearly independent pairwise comparisons among the estimated marginal means.

Table 5 Shows the regression analysis of the predictive variables related to self-efficacy.

\begin{tabular}{|c|c|c|c|c|c|c|}
\hline \multirow{2}{*}{ Model } & & \multicolumn{2}{|c|}{$\begin{array}{l}\text { Unstandardized } \\
\text { Coefficients }\end{array}$} & \multirow{2}{*}{$\begin{array}{l}\text { Standardized } \\
\text { Coefficients } \\
\text { Beta }\end{array}$} & \multirow[t]{2}{*}{$\mathbf{t}$} & \multirow[t]{2}{*}{ Sig. } \\
\hline & & B & Std. Error & & & \\
\hline \multirow[t]{7}{*}{1} & (Constant) & 16.4 & 3.91 & & 4.17 & 0 \\
\hline & Gender & -4.8 & 2.2 & -0.41 & -2.18 & 0.032 \\
\hline & Age & 0.02 & 0.06 & 0.02 & 0.32 & 0.747 \\
\hline & education & 0.51 & 0.5 & 0.11 & 1.02 & 0.312 \\
\hline & Marital & 0.81 & 1.1 & 0.08 & 0.74 & 0.464 \\
\hline & Diagnosis & 7.34 & 2.03 & 0.68 & 3.63 & 0.001 \\
\hline & type of patient & 3.21 & 1.18 & 0.3 & 2.71 & 0.008 \\
\hline
\end{tabular}

a. Dependent Variable: Total SE $\mathrm{No}======$ Self efficacy

\section{Discussion}

Firstly, through the conducted assessments for self-efficacy and emotional intelligence the results showed a relationship between self-efficacy and emotional intelligence however, no correlation was found with the quality of life in this study. This is partially consistence with the first hypothesis; there are significant relationships between cancer patient's self-efficacy, emotional intelligence, and quality of life. The patients had a wide range of scores on both tests. For the emotional intelligence, the minimum score is 105 and self-efficacy is 17 while the average scores for the EI between 160 to 30 and SE 40 to 10 . Therefore, during the interview it was felt that the vast majority of patients were excessively emotional, confident and optimistic that they were going to pass this experience (cancer) in a positive manner. The significant relationship between the self-efficacy and quality of life in terms of physical domain $\mathrm{PH}$, is in congruence with the health action process approach that self- efficacy appraisal captures an individual's confidence that $\mathrm{s} / \mathrm{he}$ is able to deal with the present situation. Individuals with higher levels of self-efficacy tend to have both lower subjective stress and increased cellular immunity.

This study also found that there is a significant effect of both gender and diagnosis on self-efficacy; The GI cancer patients had higher self-efficacy in comparison to the breast cancer patients, and the male patients had higher self-efficacy than the females. Furthermore, the results of regression analysis demonstrated that the level of self-efficacy can be predicted from patients' gender, type of cancer and from whether the patients are inpatients or outpatients. As expected, outpatients showed higher level of self-efficacy, since most of them are in their earlier stages of the disease. These findings are consistent with other studies which also reported significant effects of cancer type on the self-efficacy and quality of life of the cancer's patients. However, the percentage of female's patients in the sample with GI cancer was $25 \%$, while the $75 \%$ was males. Lastly, significant effects for females in relation to the quality of life and the mental health domains were found. This could be attributed to the type of patients, the female outpatient participants presented with $72 \%$, while for the inpatient it was only $28 \% .18-49$

\section{Conclusion}

The study showed a correlation between the self-efficacy and emotional intelligence, and a statistically significant relationship between the self-efficacy and quality of life on the physical domain only. In addition, there is a gender and diagnosis type differences, with male cancer patients having higher self-efficacy in comparison to female cancer patients. Furthermore, females have higher quality of life in terms of the mental health domain in comparison to males.

\section{Acknowledgements}

Firstly, I am eternally grateful to God for the good health and wellbeing throughout life and for the countless blessings to date, which allowed me to complete this project, and for surrounding me with lovely supportive family and friends.

I would like to express my sincere gratitude to my adviser and supervisor Dr. Mohamed S. Khalil for his continuous support, guidance, patience, valuable feedback, motivation, and constant encouragement throughout the project.

Sincere gratitude also to Dr. Amani S. Khalil, Dr. Hani Al-Hashmi and the research Department and administration at King Fahad Specialist hospital-Dammam for their help and support.

In addition to this, I would like to extend my gratitude to Dr. Maan for the valuable feedback and continuous encouragement for the golden educational activities, which helped to enhance the program 
with valuables outcomes. There are many individuals who helped on this journey and I extend my deepest gratitude to all the professionals and to the university, which gave the excellent opportunity to do this project.

Finally, a special thanks to all participants for their cooperation, patience and participating while they are in pain and receiving the treatment courses. Without them, this project would not have been possible. I wish them all a full and speedy recovery from their illness, and the best of both this life and the next.

\section{Conflict of interest}

Author declare that there is no conflict of interest.

\section{Referenes}

1. World Health Organisation. Cancer: 2018.

2. Bazarbashi SN. Saudi oncology society clinical management guidelines development. Special Communication: Saudi Med J. 2014;35(12):15241526.

3. Orley J, Kuyken, W. Quality of Life Assessment: International Perspectives. Proceedings of the Joint-Meeting Organized by the World Health Organization and the Fondation IPSEN in Paris. 1993.

4. Mayer JD, Salovey P, Caruso DR. Emotional Intelligence: Theory, Findings, and Implications. Psychological Inquiry. 2004;15(3):197-215.

5. Bandura A. Social Learning Theory. Englewood Cliffs, NJ: Prentice Hall. 1977:247.

6. Bandura A. Social Foundations of Thought and Action: A Social Cognitive Theory. Englewood Cliffs, NJ: Prentice-Hall. 1986.

7. Bandura A. Self-Efficacy: The Exercise of Control. New York: Freeman. 1997.

8. Amirifard N, Choubsaz M, Farshchian N, et al. The Incidence and survival outcome of rectal cancer: a study in the west of Iran. Scholar J Appl Med Sci. 2016;4:683-686.

9. Moradi R, Roudi MA, Kiani MM, et al. Investigating the Relationship between Self-efficacy and Quality of Life in Breast Cancer Patients Receiving Chemical Therapy. Bali Medical Journal, 2017;6(1):6-11.

10. De Castro EK, Ponciano C, Meneghetti B, et al. Quality of Life, SelfEfficacy and Psychological Well-Being in Brazilian Adults with Cancer: A Longitudinal Study. Psychology, 2012;3(4):304-309.

11. Stangor C. Research Methods for the Behavioral Sciences. $4^{\text {th }}$ ed. Mountain View, Ca: Cengage; 2011.

12. Pfeffermann DC, Rao R. Handbook of Statistics. Sample Surveys: Theory, Methods and Inference. Amsterdam: Elsevier B. V. 2009;29A.

13. Salovey P, Mayer JD. Emotional Intelligence. Imagination, Cognition and Personality. 1990;9(3):185-211.

14. Schutte NS, Malouff JM, Hall LE, et al. Development and validation of a measure of emotional intelligence. Personality and Individual Differences, 1998;25(2):167-177.

15. Schwarzer R, Luczczynska A. Self-efficacy and health behavior theories. Perceived Self-Efficacy. 1995:1-33.

16. Singh A, Gnanalingham K, Casey A, et al. Quality of life assessment using the short form-12 (SF-12) questionnaire in patients with cervical spondylotic myelopathy. Spine. 2006;31(6):639-643.

17. Wiedenfield SA, O Leary A, Bandura A, et al. Impact of perceived selfefficacy in coping with stressors on components of the immune system. $J$ Pers Soc Psychol. 1990;59:1082-1094.
18. Al Gaai EA, Hammami MM, Al Eidan M. Documentation of ethical conduct of human subject research. Eastern Mediterranean Health Journal. 2012;18:682-686.

19. American Cancer Society. What is breast cancer.

20. Australasian Gastro-Intestinal Trials Group. GI cancer.

21. Bandura A. On the functional of properties of perceived self-efficacy revisited. Journal of Management. 2012;38 (1):9-44.

22. Bandura A. Self-efficacy. In Encyclopedia of Human Behavior. VS Ramachaudran, editor. New York: Academic Press; 1994;4:71-81.

23. Bandura A. Self-efficacy in changing societies. New York: Cambridge University Press; 1995.

24. Bottomley A. The cancer patient and quality of life. The Oncologist. 2002;7(2):120-125.

25. Cherry K. Self-efficacy: why believing in yourself matters. 2017.

26. Curtis R, Groarke AM, Sullivan F. Stress and self-efficacy predict psychological adjustment at diagnosis of prostate cancer. Sci Rep. 2014;4:55-69.

27. Emotional Intelligence. London: 2010.

28. Israel G D. Determining sample size. 1992.

29. Haugland T, Wahl AK, Hofoss D, et al. Association between general selfefficacy, social support, cancer-related stress and physical health-related quality of life: A path model study in patients with neuroendocrine tumors. Health and Quality of Life Outcomes. 2016;14:11-24.

30. Hejmadi M. Introduction to Cancer Biology. $2^{\text {nd }}$ edition. London: Bookboon; 2010.

31. Juczynski Z. Health-related quality of life. Theory and Management. 2006.

32. Kreitler S, Peleg D, Ehrenfeld M. Stress, Self-efficacy and Quality of Life in Cancer Patients. Psychooncology. 2007;16(4):329-341.

33. Miller Keane Encyclopedia and Dictionary of Medicine, Nursing, and Allied Health. $7^{\text {th }}$ edition. Philadelphia: Saunders. 2003.

34. Rabindranath J P. Emotional Intelligence and Psychological Well-Being in Male and Female Individuals Treated for Head and Neck Cancer. Global JBiol Agri Health Sci. 2014;3(1):48-51.

35. Redmond, Slaugenhoup. Self-efficacy and social cognitive theories. 2016.

36. Rey L, Extremera N, Trillo L. Exploring the Relationship Between Emotional Intelligence and Health-Related Quality of Life in Patients with Cancer. J Psychosoc Oncol. 2013;31:51-64.

37. Sarrionandia AP, Mikolajczak M, Gross JJ. Integrating emotion regulation and emotional intelligence traditions: a meta analysis. Front Psychol. 2015;6:160.

38. Schipper H, Clinch JJ, Olweny CLM. Quality of life studies: definitions and conceptual issues, In Quality of Life and Pharmacoeconomics in Clinical Trials. Spilker B, editor. Philadelphia: Lippincott-Raven Publishers; 1996;17(6):548-549.

39. Schwarzer R, Renner B. Health-Specific Self-Efficacy Scales. 2009.

40. Schwarzer R, Jerusalem M. Generalized self-efficacy scale. In Measures in Health Psychology: A User's Portfolio. Causal and Control Beliefs. J Weinman, S Wright, M Johnston, editors. Windsor UK: NFER Nelson; 1995;35-37.

41. Söderlund A, Sterling M. Effect of verbal persuasion on self-efficacy for pain-related diagnostic sensory testing in individuals with chronic neck pain and healthy controls: A Randomized, Controlled Trial. J Pain Res. 2016;9:115-122. 
42. Theofilou P. Quality of life: definition and measurement. Europe $J$ Psychol. 2013;9:150-162.

43. The health psychology reader. David Marks: Sage; 2002.

44. World Health Organization. WHOQOL User Manual. Geneva, Switzerland: World Health Organization, Program on Mental Health. 1998

45. World Health Organization. WHOQOL User Manual. Geneva, Switzerland: World Health Organization, Program on Mental Health. 1998

46. Yeung NCY, Lu Q. Affect as a mediator between self-efficacy and quality of life among Chinese cancer survivors in China. Eur J Cancer Care, 2014;23(1):149-155.
47. Almutairi KM, Mansour EA, Vinluan JM. A Cross-Sectional Assessment of Quality of Life of Breast Cancer Patients in Saudi Arabia. Public Health. 2016;136:117-125.

48. Ghafarpor S, Aeinfar M, Amirifard N, et al. A Survey on the Relationship between Emotional Intelligence and Level of Depression and Anxiety among Women with Breast Cancer. Int J Hematol Oncol Stem Cell Res. 2018;11(1):54-57.

49. Redmond BF. Slaugenhoup EL. Self-efficacy and social cognitive theory. 2016. 